\title{
Kebahagiaan Autentik dan Keterikatan Kerja Guru di Sekolah Inklusi
}

\section{Ike Agustina}

Program Studi Psikologi, Fakultas Psikologi dan Ilmu Sosial Budaya, Universitas Islam Indonesia, Yogyakarta

Abstrak. Seorang pekerja diharapkan dapat memberikan kontribusi pada organisasinya. Salah satu aspek yang memiliki peranan penting dalam kualitas kontribusi seorang pekerja di tempat kerjanya adalah kebahagiaan. Penelitian ini bertujuan untuk mencari hubungan antara kebahagiaan autentik dan keterikatan kerja pada guru di sekolah inklusi. Hipotesis diuji berdasarkan asumsi bahwa kebahagiaan autentik berkorelasi dengan keterikatan kerja para guru di sekolah inklusi. Responden penelitian ini melibatkan 70 orang guru dari sekolah inklusi di Yogyakarta yang dipilih dengan menggunakan purposive sampling. Rentang usia responden antara 23 - 48 tahun. Data dikumpulkan melalui Authentic Happiness Inventory yang dimodifikasi dari Schueller dan Seligman (2010) dan Peterson (2005), sementara Utrecht Work Engagement Scale (UWES) dikembangkan oleh Schaufeli dan Bakker (2003). Hasil analisis menggunakan teknik korelasi Spearman menunjukkan besarnya koefisien antara variabel kebahagiaan autentik dan keterikatan kerja $(r=.439, p=.00[p<.05])$. Hal ini menunjukkan bahwa terdapat hubungan positif yang signifikan antara kebahagiaan autentik dan keterikatan kerja pada guru sekolah inklusi di Yogyakarta, sehingga dapat disimpulkan bahwa semakin tinggi kebahagiaan autentik maka akan semakin tinggi keterikatan kerja yang dimiliki. Hipotesis yang diajukan pada penelitian ini diterima.

Kata Kunci: kebahagiaan autentik, keterikatan kerja, guru sekolah inklusi

\section{Authentic Happiness and Work Engagement among Teachers in Inclusive School}

Abstract. Employees are expected to provide significant contributions to their organization. One aspect that has an important role in the quality of employees' contibution at their workplace is happiness. This study aims to explore the relationship between authentic happiness and work engagement of teachers in inclusive schools. The hypothesis to be examined based on the assumption that the authentic happiness correlated with the work engagement of teachers in inclusive school. Seventy (70) teachers from inclusive schools in Yogyakarta taken based on purposive sampling. The age of subjects were in the range of $23-48$ years. Data collected in this study was then analyzed using Authentic Happiness Inventory which modified from Schueller and Seligman (2010) and Peterson (2005), while Utretch Work Engagement Scale (UWES) was developed by Schaufeli and Bakker (2003). The Results of analysis using Spearman's correlation technique showed the coefficient between the variables $(r=.439, p=$ $.000[p<.05])$. This study indicates that there is a significant positive relationship between happiness and work enggagement of teachers in inclusive schools. Furthermore, The higher the happiness, the higher the work engagement they have. The proposed hypothesis in this study is acceptable.

Keywords: authentic happiness, teachers of inclusive school, work engagement

Korespondensi: Ike Agustina. Email: ike.agustina@uii.ac.id 
Perkembangan pelaksanaan pendidikan bagi Anak Berkebutuhan Khusus (ABK) di Indonesia secara formal berlangsung sejak berdirinya Sekolah Luar Biasa (SLB) (Sunanto, 2007). Dalam perkembangannya, layanan pendidikan ABK yang sekarang marak di sekolah-sekolah reguler adalah pendidikan inklusif. Prinsip dasar dari pendidikan inklusif adalah proses pendidikan yang menghadirkan individu berkebutuhan khusus untuk mengikuti pendidikan di sekolah reguler (Hermanto, 2010). Pelaksanaan pendidikan bagi ABK berlangsung secara terpadu bersama dengan anak-anak lain pada umumnya (Sunanto, 2007). Dengan demikian, ABK tetap mendapatkan hak pendidikannya di sekolahsekolah inklusi.

Merangkum dari yang disampaikan Wartomo (2016) bahwa terdapat beberapa indikator yang harus menjadi perhatian bagi penyelenggara pendidikan inklusi. Walaupun demikian, Wartomo (2016) menambahkan bahwa masih terdapat kesenjangan antara indikator yang harus dimiliki dengan apa yang terjadi di lapangan, khususnya sekolahsekolah inklusi di wilayah Daerah Istimewa Yogyakarta (DIY). Misalnya, dari indikator ketenagaan yang ada di sekolah-sekolah inklusi di DIY, yaitu sekolah tidak memiliki guru pendamping khusus untuk mendampingi siswa ABK dalam mengikuti pembelajaran. Selain itu, sekolah belum menyediakan tenaga profesional nonguru untuk membantu ABK yang memiliki hambatan belajar seperti dokter, terapis, dan psikolog.

Berkaitan dengan tenaga pengajar untuk pendidikan inklusif (Guru Pendamping Khusus/GPK), sebenarnya pemerintah telah mengatur dalam dua peraturan yaitu Peraturan Pemerintah (PP) No. 19 Tahun 2005 tentang Standar Nasional Pendidikan, dan Peraturan Menteri Pemberdayaan Aparatur Negara dan Reformasi Birokrasi (Permen PAN-RB) No. 16 Tahun 2009 tentang Profesi Guru dan Angka Kreditnya. Selain itu, ada juga Peraturan Menteri Pendidikan Nasional (Permendiknas) Nomor 70 Tahun 2009 yang menguraikan tentang tugas GPK di sekolah inklusi, yakni pertama, menyusun instrumen asesmen pendidikan bersamasama dengan guru kelas dan guru mata pelajaran. Kedua, membangun sistem koordinasi antara guru, pihak sekolah, dan orang tua. Ketiga, melaksanakan pendampingan ABK pada kegiatan pembelajaran bersama dengan guru kelas, guru mata pelajaran, dan guru bidang studi. Keempat, memberikan bantuan layanan khusus bagi ABK yang mengalami hambatan dalam mengikuti pembelajaran. Kelima, memberikan bimbingan secara berkesinambungan dan membuat catatan khusus kepada ABK. Keenam, memberikan bantuan kepada guru kelas, guru mata pelajaran, dan guru bidang studi agar mereka dapat memberikan pelayanan pendidikan kepada ABK. 
Gambaran tentang sekolah inklusi di atas menunjukkan bahwa tanggung jawab yang harus diemban para guru di sekolah inklusi sangat berbeda dengan apa yang dihadapi para guru di sekolah reguler, sehingga hal ini berdampak pada keterikatan kerja pada guru di sekolah inklusi (Minghui et al., 2018). Keterikatan kerja yang tinggi pada guru yang mengajar siswa berkebutuhan khusus akan memberi dampak positif pada keadaan resilien ketika menghadapi berbagai tekanan di dalam pekerjaan (Asfiyah \& Kurniawati, 2014). Manfaat keterikatan kerja yang dimiliki oleh seorang guru pada latar pendidikan inklusif akan memberi gambaran pada beragamnya pola pembelajaran yang diterapkan di kelas (Mäkinen, 2013). Situasi-situasi inilah yang menuntut setiap guru di sekolah inklusi agar memiliki keterikatan kerja yang tinggi.

Keterikatan kerja berkaitan dengan perilaku seseorang untuk mengikatkan diri pada suatu pekerjaan. Keterikatan kerja ini berkaitan erat atau bahkan mungkin merupakan unsur pembentuk dari apa yang disebut dengan sebuah kombinasi dari kepuasan kerja atau "The A (attitude)-factor", keterlibatan kerja, dan komitmen organisasional afektif (Newman et al, 2010). Keterikatan kerja terjadi ketika seorang pekerja mengetahui apa yang diharapkan, mendapatkan sumber daya untuk menyelesaikan pekerjaan, memiliki kesempatan untuk berpartisipasi terhadap pengembangan serta mendapatkan umpan balik, dan merasa bahwa kontribusi yang diberikan terhadap organisasi dapat diterima atau diapresiasi (Batista-Taran et al., 2009). Menurut Gorgievski dan Schaufeli (2010), seorang pekerja yang memiliki keterikatan kerja yang baik memiliki kecenderungan untuk lebih mampu menangkap peluang-peluang yang ada dan secara sosial lebih mampu mengembangkan jejaring yang dimilikinya.

Schaufeli et al. (2002) mendefinisikan keterikatan kerja sebagai suatu kondisi mental yang positif terkait dengan pekerjaan yang mempunyai karakteristik (a) semangat, (b) dedikasi, dan (c) penghayatan. Semangat ditandai oleh energi dan ketahanan mental tingkat tinggi saat bekerja, kemauan untuk menginvestasikan upaya dalam pekerjaan seseorang, dan kegigihan bahkan dalam menghadapi kesulitan. Dedikasi mengacu pada keterlibatan kuat dalam pekerjaan seseorang, merasa bahwa pekerjaannya penting, antusiasme, inspirasi, kebanggaan, dan tantangan. Lebih lanjut, penghayatan ditandai dengan sepenuhnya terkonsentrasi dan tenggelam dalam pekerjaan, di mana waktu berlalu dengan cepat.

Keterikatan kerja yang dimiliki seorang pekerja akan mendorongnya untuk bekerja dengan lebih bersemangat dan merasakan hubungan yang mendalam dengan organisasi, sehingga hal ini akan membuatnya bersedia mengembangkan inovasi-inovasi yang akan mendukung kemajuan organisasi. Namun demikian, kondisi ini tidak sepenuhnya 
tercapai. Gallup Consulting (Endres \& Smoak, 2008) dalam studinya yang dilakukan terhadap sejumlah individu yang bekerja di Amerika Serikat menemukan bahwa persentase pekerja yang bertindak aktif dan memiliki keterikatan kerja yang kuat hanya di angka 29\% saja, sementara 54\% lainnya tergolong dalam pekerja yang tidak memiliki keterikatan kerja baik, dan sisanya sebesar $17 \%$ bukan hanya tidak memiliki keterikatan kerja namun bahkan memiliki kecenderungan untuk menularkan sikap negatifnya, bersikap destruktif, dan memusuhi organisasi.

Hasil riset yang dilakukan Gallup Consulting (2008) tersebut tampaknya selaras dengan apa yang diperoleh dari studi yang dilakukan oleh Global Workforce pada tahun 2012 di Indonesia, di mana ditemukan bahwa $27 \%$ individu yang bekerja setidaknya dalam dua tahun mendatang berencana untuk meninggalkan pekerjaannya. Bahkan, sebanyak $42 \%$ individu yang bekerja yakin bahwa mereka akan berpindah organisasi karena alasan peningkatan kariernya di masa depan. Hasil studi tersebut juga mengungkapkan bahwa sekitar 38\% pekerja yang tidak terikat cenderung akan meninggalkan pekerjaannya dalam dua tahun. Sebaliknya, hanya 21\% pekerja yang merasa terikat ingin meninggalkan organisasinya saat itu juga dalam periode yang sama (Endres \& Smoak, 2008).

Kondisi-kondisi yang digambarkan dalam dua studi tersebut menyiratkan bahwa problematika terkait keterikatan kerja perlu mendapatkan perhatian serius. Keterikatan kerja yang rendah pada seorang pekerja dapat menimbulkan efek negatif dalam proses bisnis di organisasi yang selanjutnya akan menurunkan performansi organisasi secara keseluruhan (Rooy et al., 2011; Sungkit \& Meiyanto, 2015). Gallup (Bhatnagar, 2007) menambahkan bahwa pekerja yang tidak memiliki keterikatan dengan organisasi tempat mereka bekerja sering kali menunjukkan sikap sinis di lingkungan kerja dan cepat mengalami kelelahan. Sebaliknya, seorang pekerja yang memiliki perasaan terikat dengan organisasi di tempatnya bekerja menunjukkan sikap efektif (Bakker \& Leiter, 2010). Secara khusus, penelitian Høigaard et al. (2011) terhadap 192 orang guru di Norwegia menunjukkan bahwa keterikatan kerja dan efikasi diri para guru berkorelasi positif dengan kepuasan kerja dan berkorelasi negatif dengan kelelahan kerja (burnout) serta intensi untuk keluar dari pekerjaan.

Beberapa variabel terkait dengan latar kerja yang selama ini sering diasosiasikan dengan tumbuhnya keterikatan kerja para pekerja, antara lain adalah persepsi atas dukungan organisasi dan perilaku proaktif di tempat kerja (Botha \& Mostert, 2014; Els et al., 2016; Mphahlele et al, 2018) dan variabilitas intraindividu dalam pengalaman seorang pekerja di tempat kerja (Bakker \& Bal, 2010). Namun demikian, Bakker (2011) menyatakan bahwa keterikatan kerja seorang pekerja 
setidaknya dipengaruhi oleh dua sumber daya utama, yaitu sumber daya kerja (job resources) dan sumber daya pribadi (personal resources). Sumber daya kerja terdiri atas aspek-aspek fisik, sosial, maupun organisasi yang berperan sebagai media untuk mencapai tujuan pekerjaan, mengurangi tuntutan kerja, serta menstimulasi pertumbuhan dan perkembangan individu. Sementara itu, sumber daya personal merupakan aspek-aspek diri individu yang dihubungkan dengan kegembiraan dan perasaan bahwa diri mampu memanipulasi, mengontrol, serta memberikan dampak pada lingkungan sesuai dengan keinginan dan kemampuannya (Bakker \& Demerouti, 2008). Dijelaskan lebih lanjut oleh Schaufeli (2013) bahwa sumber daya personal ini dapat berwujud efikasi diri, optimisme, dan kemampuan untuk mengelola kondisi emosi agar tetap stabil.

Berkaitan dengan sumber daya personal tersebut, Gupta (2012) menyebutkan bahwa seseorang yang bahagia di tempat kerja akan cenderung merasa lebih bahagia di rumah, memiliki kecerdasan emosi yang lebih baik, meningkat fokus kerjanya, mencintai pekerjaannya, menghargai posisi atau jabatan yang diembannya, dan lebih merasa dihargai. Hal ini mengindikasikan bahwa kebahagiaan memiliki peran dalam membangun dan mengembangkan keterikatan kerja seorang pekerja. Salah satu konsep kebahagiaan yang bersifat mendasar sejalan dengan peran dari sumber daya personal adalah kebahagiaan autentik, di mana sumber kebahagiaan adalah sesuatu yang berasal dari dalam diri seseorang yang berkaitan dengan kemampuannya mengelola kehidupan yang dijalaninya dengan perasaan positif.

Seligman (2005) dalam konsep kebahagiaan yang dibangunnya mendefinisikan kebahagiaan autentik sebagai keadaan psikologis yang dialami oleh individu yang ditandai dengan (a) adanya emosi-emosi positif, (b) larut dan menikmati aktivitasaktivitas yang dilakukan, serta (c) memiliki penghayatan yang mendalam akan tujuan dan makna hidup. Hasil penelitian yang dilakukan oleh Seligman menyebutkan bahwa terdapat tiga cara untuk mencapai kebahagiaan autentik. Pertama, melalui kesenangan atau kenikmatan yang melibatkan pengalaman mengenai emosi-emosi positif di masa lalu (pemaafan dan kepuasan), masa sekarang (kegembiraan dan kegemaran) dan masa mendatang (optimisme dan harapan). Kedua, melalui kebermaknaan yang mana untuk mencapai kebahagiaan ditempuh melalui keterikatan terhadap sesuatu yang lebih besar daripada dirinya, dan memiliki penghayatan yang mendalam atas tujuan atau makna hidup. Terakhir, melalui keadaan mengalir yang berarti situasi di mana seseorang tenggelam dengan apa yang sedang dilakukannya.

Penelitian-penelitian kebahagiaan autentik yang berperan positif pada keterikatan kerja telah dilakukan sebelumnya. Field dan Buitendach (2011) membuktikan 
bahwa perasaan positif di lingkungan kerja berkorelasi dengan keterikatan kerja. Swart dan Rothmann (2012) dalam penelitian yang dilakukan pada 507 pekerja mendapatkan hasil bahwa afek positif (kebahagiaan) berkorelasi positif secara signifikan dengan keterikatan kerja. Studi-studi terbaru yang dilakukan juga konsisten menunjukkan hasil serupa. De Stasio et al. (2019) dalam penelitiannya terhadap 187 orang guru yang bekerja penuh waktu di Italia membuktikan bahwa kebahagiaan dan kasih sayang berkorelasi dengan keterikatan kerja para guru. Demikian pula halnya dengan penelitian terhadap 472 orang guru sekolah menengah di China yang menunjukkan kontribusi kebahagiaan sebagai prediktor bagi keterikatan kerja (Zeng et al, 2019).

Berdasarkan uraian di atas, penelitian ini bertujuan untuk mengetahui peranan dari kebahagiaan autentik pada keterikatan kerja guru di sekolah inklusi. Hal ini menjadi kelebihan dari penelitian ini, sebab konteks pengambilan data di sekolah inklusi yang relatif masih jarang diteliti. Hipotesis yang dibangun dengan asumsi bahwa kebahagiaan akan berkorelasi positif dengan keterikatan kerja guru di sekolah inklusi, di mana semakin tinggi kebahagiaan autentik, maka semakin tinggi pula tingkat keterikatan kerja guru di sekolah inklusi.

\section{Metode}

\section{Subjek penelitian}

Subjek dalam penelitian ini merupakan guru yang bekerja di sekolah inklusi di
Yogyakarta berjumlah 70 orang dengan rentang usia antara 23 - 48 tahun, di mana subjek penelitian mengisi skala yang dibagikan secara manual. Pemilihan subjek dilakukan dengan menggunakan teknik purposive sampling.

\section{Metode pengumpulan data}

\section{Kebahagiaan autentik}

Kebahagiaan autentik dalam penelitian ini diukur dengan menggunakan Authentic Happiness Inventory yang dimodifikasi dari Schueller dan Seligman (2010) dan Peterson (2005). Authentic Happiness Inventory terdiri dari 23 butir pernyataan yang merupakan gabungan dari tiga aspek, yaitu: kenikmatan, keterikatan, dan kebermaknaan. Setiap nomor butir akan memiliki lima alternatif pernyataan yang salah satunya harus dipilih subjek penelitian. Contoh salah satu nomor butir dalam skala ini, di antaranya "Saya mengalami lebih banyak duka daripada kesenangan", "Saya mengalami duka dan kesenangan dalam jumlah yang sama”, "Saya mengalami lebih banyak kesenangan daripada duka", "Saya mengalami jauh lebih banyak kesenangan daripada duka", dan "Hidup saya penuh dengan kesenangan". Untuk setiap nomor butir, skor minimum adalah 1 dan skor maksimum adalah 5. Skor total yang diperoleh oleh subjek penelitian dari skala kebahagiaan autentik ini menunjukkan tingkat kebahagiaan autentik yang dimilikinya. Semakin tinggi skor total dari skala kebahagiaan autentik, maka semakin tinggi 
tingkat kebahagiaan autentik subjek penelitian. Sebaliknya, semakin rendah skor total yang diperoleh subjek penelitian dari skala kebahagiaan autentik, maka semakin rendah tingkat kebahagiaannya. Koefisien korelasi butir-total bergerak dari .331 sampai .680 dan koefisien reliabilitas Alpha Cronbach sebesar 895 .

\section{Tabel 1}

Distribusi Butir Soal dalam Skala Kebahagiaan Autentik

\begin{tabular}{lcc}
\hline \multicolumn{1}{c}{ Aspek } & Nomor butir & Jumlah \\
\hline Kenikmatan & $2,5,13,21$ & 4 \\
Keterikatan & $3,6,10,12,14,18,22$ & 7 \\
Kebermaknaan & $1,4,7,8,9,11,15$, & 12 \\
Jumlah & $16,17,19,20,23$ & 23 \\
\hline
\end{tabular}

\section{Keterikatan kerja}

Pengukuran atas variabel keterikatan kerja dilakukan dengan menggunakan The Utrecht Work Engagement Scale (UWES) yang diadaptasi dari Schaufeli dan Bakker (2003). Utrecht Work Engagement Scale (UWES) terdiri dari 17 butir pernyataan yang merupakan gabungan dari tiga aspek utama dalam keterikatan kerja. Pada skala ini, subjek penelitian diminta untuk memilih satu dari tujuh alternatif jawaban yang tersedia, yaitu 0 (tidak pernah), 1 (beberapa kali dalam setahun atau kurang), 2 (sekali dalam sebulan atau kurang), 3 (beberapa kali dalam sebulan), 4 (seminggu sekali), 5 (beberapa kali dalam seminggu), dan
6 (setiap hari). Contoh dari butir yang ada dalam skala ini, antara lain "Saya merasa antusias dengan pekerjaan saya" dan "Ketika saya bangun di pagi hari, saya merasa bersemangat untuk kerja". Skor total dalam skala keterikatan kerja ini mencerminkan tingkat keterikatan kerja subjek penelitian. Semakin tinggi skor total yang diperoleh, maka hal tersebut menunjukkan bahwa semakin tinggi tingkat keterikatan kerja yang dimiliki oleh subjek penelitian. Sebaliknya, jika skor total yang diperoleh semakin rendah, maka tingkat keterikatan kerja akan semakin rendah. Koefisien korelasi butir-total bergerak dari .319 sampai .736 dan koefisien reliabilitas Alpha Cronbach sebesar .909.

\section{Tabel 2}

Distribusi Butir Soal dalam Keterikatan Kerja

\begin{tabular}{lcc}
\hline \multicolumn{1}{c}{ Aspek } & Nomor butir & Jumlah \\
\hline Semangat & $1,4,8,12,15,17$ & 6 \\
Dedikasi & $2,5,7,10,13$ & 5 \\
Penghayatan & $3,6,9,11,14,16$ & 6 \\
Jumlah & & 17 \\
\hline
\end{tabular}




\section{Metode analisis data}

Tujuan dari penelitian ini adalah untuk melihat hubungan antara kebahagiaan autentik dengan keterikatan kerja pada pekerja yang merupakan guru di sekolah inklusi. Berdasarkan tujuan tersebut, hipotesis penelitian ini diuji dengan menggunakan teknik korelasi Spearman.

\section{Hasil}

Berdasarkan kuesioner yang telah dibagikan kepada 70 orang subjek penelitian, diperoleh data demografi sebagaimana tercantum dalam tabel berikut ini.

Tabel 3

Deskripsi Subjek Penelitian

\begin{tabular}{lccc}
\hline \multicolumn{1}{c}{ Faktor } & Kelompok & Jumlah & Persentase \\
\hline \multirow{2}{*}{ Jenis Kelamin } & Laki-laki & 11 & $16 \%$ \\
Masa Kerja & Perempuan & 59 & $84 \%$ \\
& $<1$ Tahun & 14 & $20 \%$ \\
& $1-2$ Tahun & 13 & $19 \%$ \\
& $2-5$ Tahun & 31 & $44 \%$ \\
Usia & $>5$ Tahun & 12 & $17 \%$ \\
& $<25$ Tahun & 9 & $13 \%$ \\
Pendidikan & 25 - 30 Tahun & 39 & $56 \%$ \\
& 30 - 35 Tahun & 13 & $18 \%$ \\
\multirow{3}{*}{ Status Pernikahan } & 35 Tahun & 9 & $13 \%$ \\
& Diploma & 2 & $3 \%$ \\
& Sarjana & 62 & $88 \%$ \\
& Magister & 6 & $9 \%$ \\
& Menikah & 40 & $57 \%$ \\
& Belum Menikah & 25 & $36 \%$ \\
\hline
\end{tabular}

Tampak dari data pada Tabel 3 bahwa subjek penelitian ini didominasi oleh perempuan menikah yang merupakan sarjana dengan rentang usia antara 25 - 30 tahun dan $44 \%$ dari total subjek tersebut memiliki masa kerja antara 2 - 5 tahun. Sementara itu, berdasarkan hasil pengolahan data statistika, diperoleh kategorisasi subjek penelitian untuk variabel kebahagiaan autentik sebagaimana tercantum dalam Tabel 4.

\section{Tabel 4}

Kategorisasi Subjek Berdasarkan Skor Kebahagiaan Autentik

\begin{tabular}{lccc}
\hline \multicolumn{1}{c}{ Kategori } & Skor & Jumlah & Persentase \\
\hline Sangat Tinggi & $\mathrm{X} \geq 106.58$ & 1 & $1 \%$ \\
Tinggi & $93.19 \leq \mathrm{X}<106.58$ & 3 & $4 \%$ \\
Sedang & $79.81 \leq \mathrm{X}<93.19$ & 21 & $30 \%$ \\
Rendah & $66.41 \leq \mathrm{X}<79.81$ & 36 & $52 \%$ \\
Sangat Rendah & $\mathrm{X}<66.41$ & 9 & $13 \%$ \\
\hline
\end{tabular}


Berdasarkan Tabel 4 tampak bahwa kebahagiaan autentik subjek penelitian yang masuk dalam kategori sangat tinggi berjumlah satu subjek (1\%), kategori tinggi berjumlah tiga subjek (4\%), kategori sedang berjumlah 21 subjek (30\%), kategori rendah berjumlah 36 subjek (52\%), dan kategori sangat rendah berjumlah sembilan subjek
(13\%). Meskipun perhitungan rerata skor total subjek untuk variabel kebahagiaan autentik ini berada pada skor 82 , namun secara umum lebih dari separuh subjek penelitian memiliki level kebahagiaan autentik pada kategori rendah (52\%) dengan rentang skor pada kategori rendah adalah $66.41 \leq \mathrm{X}<79.81$.

\section{Tabel 5}

Kategorisasi Subjek Berdasarkan Skor Keterikatan Kerja

\begin{tabular}{lccc}
\hline \multicolumn{1}{c}{ Kategori } & Skor & Jumlah & Persentase \\
\hline Sangat Tinggi & $\mathrm{X} \geq 88.39$ & 18 & $26 \%$ \\
Tinggi & $74.78 \leq \mathrm{X}<88.39$ & 32 & $46 \%$ \\
Sedang & $61.22 \leq \mathrm{X}<74.78$ & 14 & $20 \%$ \\
Rendah & $47.61 \leq \mathrm{X}<61.22$ & 3 & $4 \%$ \\
Sangat Rendah & $\mathrm{X}<47.61$ & 3 & $4 \%$ \\
\hline
\end{tabular}

Tabel 5 menunjukkan bahwa tingkat keterikatan kerja pada kategori sangat tinggi berjumlah 18 subjek (26\%), kategori tinggi memiliki jumlah yang sama yaitu 32 subjek (46\%), kategori sedang memiliki jumlah subjek yang sama yaitu 14 subjek (20\%), dan kategori rendah dan sangat rendah memiliki jumlah subjek yang sama yaitu tiga subjek (4\%). Berdasarkan hasil kategori pada tabel di atas dapat disimpulkan bahwa keterikatan kerja mayoritas subjek penelitian berada pada kategori tinggi (46\%) dengan rentang skor pada kategori tinggi adalah $74.78 \leq \mathrm{X}<88.39$.

\section{Uji hipotesis}

\section{Tabel 6}

Hasil Uji Hipotesis Kebahagiaan Autentik dan Keterikatan Kerja

\begin{tabular}{cccc}
\hline Variabel & $r$ & $r^{2}$ & $p$ \\
\hline Kebahagiaan autentik*keterikatan kerja & .439 & .193 & .000 \\
\hline
\end{tabular}

Merujuk pada hasil uji asumsi di mana data penelitian terdistribusi tidak normal dan hubungan antara dua variabel tersebut linier, maka uji hipotesis pada penelitian ini dilakukan dengan menggunakan teknik korelasi Spearman. Hasil uji korelasi yang telah dilakukan menunjukkan besarnya koefisien korelasi antara variabel kebahagiaan autentik dan keterikatan kerja $(r=.439, p=.000[p<$ .05]). Hal ini menunjukkan bahwa terdapat hubungan positif yang signifikan antara kebahagiaan autentik dan keterikatan kerja pada subjek penelitian. Artinya, hipotesis yang diajukan pada penelitian ini diterima. 


\section{Pembahasan}

Tujuan penelitian ini adalah untuk mengetahui peranan dari kebahagiaan autentik pada keterikatan kerja guru di sekolah inklusi. Guru merupakan salah satu tokoh penting dalam praktik inklusi di sekolah, karena guru berinteraksi secara langsung dengan para siswa, baik siswa yang berkebutuhan khusus maupun siswa nonberkebutuhan khusus (Elisa \& Wrastari, 2013). Dalam praktiknya, guru di sekolah inklusi ini memiliki beban kerja yang lebih berat dibandingkan dengan guru reguler karena sebagaimana yang diketahui bahwa mendidik anak dengan kebutuhan khusus dan anak reguler dalam skema waktu yang bersamaan tentu membutuhkan kesabaran, keterampilan dan kreativitas yang lebih, serta pengetahuan yang memadai dalam menanggapi beberapa keluhan yang datang dari wali murid terkait dengan perkembangan anaknya di sekolah. Hasil penelitian Galaterou dan Antoniou (2017) menyebutkan bahwa guru di sekolah inklusi yang memiliki sikap positif tinggi cenderung akan mengalami stres kerja yang lebih minim dibandingkan dengan guru yang sikap positif nya lebih rendah.

Tantangan pekerjaan yang dialami guru di sekolah inklusi menjadikan keterikatan kerja para guru tersebut patut menjadi suatu hal yang perlu diperhatikan, terutama jika merujuk pada berbagai pemikiran yang menyebutkan konsekuensi besar dari keterikatan kerja terhadap berbagai aspek kehidupan kerja lainnya, seperti: (a) intensi yang mendalam untuk bekerja, (b) kepuasan kerja, (c) keinginan untuk bertahan di organisasi, dan (e) rendahnya tingkat konflik antara keluarga-pekerjaan (Adekola, 2011; Burke et al., 2013; Yang et al., 2000).

Penelitian ini bertujuan untuk mengetahui hubungan antara kebahagiaan autentik dan keterikatan kerja pada pekerja, khususnya guru di sekolah inklusi. Hasil uji korelasi dari Spearman menunjukkan adanya korelasi positif yang signifikan antara kebahagiaan autentik dan keterikatan kerja dengan nilai koefisien korelasi sebesar .439 dengan signifikansi sebesar .000. Artinya, hipotesis dalam penelitian ini diterima.

Temuan lain yang berhasil diungkap oleh peneliti menunjukkan bahwa 52\% subjek penelitian ini masuk dalam kategori rendah dari sisi kebahagiaan autentik dan sekitar 72\% dari total subjek penelitian memiliki keterikatan kerja yang berada pada kategori tinggi dan sangat tinggi. Tingginya level keterikatan kerja para guru ini menurut Runhaar et al. (2013) salah satunya dipengaruhi oleh penghayatan mereka yang mendalam atas perannya sebagai guru di mana mereka akan memiliki rasa puas manakala melihat murid-murid yang dibimbingnya mencapai keberhasilan, di samping adanya motivasi intrinsik di dalam diri guru untuk turut serta dalam melakukan perubahanperubahan sosial di lingkungannya melalui dunia pendidikan yang digelutinya. 
Sementara itu, besarnya sumbangan efektif kebahagiaan autentik pada keterikatan kerja dalam penelitian ini ditunjukkan dengan persentase sebesar 19.3\%. Artinya, 80.7\% dari keterikatan kerja dipengaruhi oleh faktorfaktor lainnya yang tidak diteliti dalam penelitian ini. Temuan dari penelitian ini telah menguatkan hasil riset yang dilakukan sebelumnya oleh De Stasio et al. (2019) terhadap 187 orang guru di Italia serta penelitian oleh Zeng et al. (2019) yang dilakukan di China terhadap 472 orang guru sekolah menengah yang menunjukkan pentingnya sumbangsih kebahagiaan untuk memprediksi keterikatan kerja para guru.

Menurut Veenhoven (2001), kebahagiaan sendiri sebetulnya berhubungan dengan sejauh mana individu menikmati hidupnya secara keseluruhan. Pendapat ini juga sejalan dengan konsep kebahagiaan autentik yang menggambarkan kebahagiaan seseorang, salah satunya direfleksikan pada bagaimana seseorang menikmati apa yang sedang dikerjakannya. Hal ini menyiratkan bahwa individu yang bahagia cenderung lebih mudah untuk mampu menikmati hal-hal yang sedang dilakukannya, termasuk pekerjaannya. Dalam konteks ini, keterikatan kerja yang tinggi pada diri seorang pekerja dapat muncul berdasarkan perasaan bahagia dalam menjalankan tugas-tugasnya. Jika seorang pekerja memiliki kenikmatan, keterikatan, dan kebermaknaan dalam pekerjaannya, maka dapat dikatakan pekerja tersebut mampu terlibat penuh dalam pekerjaannya. Sebaliknya, jika seorang pekerja memilih untuk melakukan pekerjaannya dengan tidak sepenuh hati maka pekerja tersebut sulit untuk terikat dalam pekerjaannya.

Christian et al. (2011) dalam penelitiannya menunjukkan bahwa pekerja yang mengalami keterikatan adalah seseorang yang melakukan pekerjaannya dengan penghayatan akan investasi diri, energi, dan gairah yang diterjemahkan ke dalam kinerja pokok (in-role) maupun kinerja tambahan (extra-role). Ketika seorang pekerja menginvestasikan energi yang dimilikinya ke dalam peran pekerjaan mereka, maka mereka akan memiliki kinerja kontekstual yang lebih tinggi. Keterlibatan kerja adalah salah satu indikator kesediaan seorang pekerja agar dapat mengeluarkan upaya yang lebih dalam untuk membantu organisasinya. Keterlibatan kerja didominasi oleh perilaku kinerja tambahan. Seorang pekerja yang mengalami keterikatan akan cenderung melakukan perilaku kinerja tambahan. Hal ini mungkin disebabkan karena mereka mampu mencapai tujuan untuk melakukan tugas-tugas mereka secara efisien, sehingga memungkinkan mereka untuk mengejar aktivitas-aktivitas yang bukan bagian dari deskripsi pekerjaan mereka. Pendapat ini dikuatkan oleh Ariani (2013) dalam penelitiannya yang melibatkan 507 partisipan yang merupakan pekerja di industri layanan yang berada di wilayah Yogyakarta, di mana 
ditemukan hasil bahwa keterlibatan kerja memiliki korelasi positif yang signifikan dengan perilaku kewargaan organisasi dan berkorelasi negatif dengan perilaku kontraproduktif. Dalam konteks di mana guru di sekolah inklusi memiliki tantangan yang besar dalam mendampingi proses belajar para siswa $\mathrm{ABK}$, maka hasil penelitian Christian etal (2011) dan Ariani (2013) ini mengindikasikan bahwa keterikatan kerja menjadi sebuah hal yang sebaiknya dimiliki guru.

Hasil yang diperoleh peneliti ini juga semakin menguatkan peranan kebahagiaan sebagai variabel yang memberikan kontribusi penting terhadap beberapa hal positif lainnya dalam kehidupan seseorang, seperti: (a) kepuasan terhadap relasi yang dimiliki, (b) kecenderungan yang lebih besar untuk melakukan perilaku prososial, (c) tingkat pendapatan yang lebih tinggi, (d) kesehatan fisik yang lebih baik, dan (e) tingkat stres yang lebih rendah (Batainerh, 2019; Chon \& Fredrickson, 2006; Fredrickson \& Joiner, 2002; Lyubomirsky \& King, 2013). Meskipun ada pendapat-pendapat yang menyebutkan bahwa mengejar kebahagiaan terkadang dianggap sebagai usaha yang bersifat hedonistik dan egois, namun penelitian yang berkembang saat ini menunjukkan bahwa konsekuensi yang bersifat interpersonal maupun intrapersonal dari menjadi bahagia lebih dari sekadar adanya perasaan positif, namun meluas dan memberikan dampak positif di lingkungan sosial maupun lingkungan kerja.
Seligman (2012) mengungkapkan bahwa kebahagiaan autentik sesungguhnya bersumber dari identifikasi seseorang atas kekuatan-kekuatan fundamental yang dimilikinya dan kemampuannya untuk menggunakan kekuatan-kekuatan tersebut setiap harinya dalam pekerjaannya, cinta kasih, maupun dalam praktik pengasuhan. Hal yang sangat prinsip dalam kebahagiaan autentik ini adalah bahwa kebahagiaan berasal dari pencapaian kekuatan diri, kebajikan, dan kehidupan yang dijiwai dengan kesejatian. Meskipun banyak kritik yang juga disampaikan atas konsep kebahagiaan autentik (Arcidiacono \& Martino, 2016), namun Seligman meyakinkankan bahwa kebahagiaan autentik ini penting, sebab kebahagiaan autentik lebih dari sekadar bagaimana seseorang mengalami kejadiankejadian yang menyenangkan, namun bagaimana seseorang mampu menghargai setiap aktivitas yang sedang dilakukan ataupun peristiwa yang dialaminya, dan ini merupakan sebuah keterampilan hidup yang penting dimiliki.

Gupta (2012) mengungkapkan bahwa seseorang yang bahagia di tempat kerja akan cenderung memiliki (a) kecerdasan emosi yang lebih baik, (b) meningkat fokus kerjanya, (c) mencintai pekerjaannya, (d) menghargai posisi atau jabatan yang diembannya, dan (e) lebih merasa dihargai. Semua hal tersebut pada gilirannya akan menumbuhkan keterikatan kerja. Selaras dengan pendapat Gupta (2012) 
tersebut, Money et al. (2009) yang banyak melakukan riset mengenai kebahagiaan mengungkapkan bahwa kebahagiaan bertindak sebagai mekanisme kausal yang membawa banyak kondisi positif di tempat kerja adalah jantung dari psikologi organisasi yang positif. Lebih jauh diungkapkan oleh para peneliti tersebut bahwa pekerjaan, melalui perspektif psikologi positif, dapat menyebabkan orang menjalani kehidupan kerja yang lebih penuh keterlibatan, menyenangkan, dan bermakna. Hal ini, pada akhirnya akan memberikan manfaat bagi pekerja maupun organisasi tempat kerja.

Melihat semakin menguatnya gagasangagasan mengenai anteseden dan konsekuensi dari keterikatan kerja ini, organisasi tentu perlu melakukan upaya-upaya sistematis untuk dapat meningkatkan level keterikatan kerja dari para pekerjanya. Studi tentang anteseden atas keterikatan kerja menunjukkan berbagai faktor yang relevan di tingkat individu, pekerjaan, tim, dan organisasi yang dapat memengaruhi keterlibatan kerja, termasuk juga di dalamnya adalah desain pekerjaan yang memungkinkan adanya otonomi dan umpan balik tentang kinerja, dan yang memastikan bahwa seorang pekerja memiliki sumber daya yang memadai dan tepat, di samping gaya kepemimpinan yang positif dan autentik (Bailey et al., 2015).

Dalam kaitannya dengan hasil penelitian ini yang menitikberatkan faktor sumber daya personal (dalam hal ini kebahagiaan autentik) sebagai anteseden keterikatan kerja, maka penting bagi pihak manajemen sekolah inklusi untuk melakukan upaya konkret yang sistematis guna membekali para guru di sekolah inklusi dengan keterampilan untuk membangun dan mengembangkan kebahagiaan autentik di dalam dirinya. Kebahagiaan autentik ini tentu menjadi sesuatu yang dibutuhkan para guru di sekolah inklusi, mengingat guru di sekolah inklusi memiliki peluang besar untuk mengalami situasi-situasi yang kurang menyenangkan akibat dari tuntutan pekerjaannya tersebut. Oleh karena itu, guru di sekolah inklusi perlu memiliki kebahagiaan autentik agar dapat menjalani aktivitas-aktivitasnya dengan emosi-emosi yang lebih positif demi mendorong tumbuhnya perasaan senang dan bermakna di saat sedang bekerja. Hal ini didukung oleh penelitian Xanthopoulou et al. (2012) yang mengungkapkan bahwa emosi positif memediasi hubungan antara sumber daya pekerjaan harian-otonomi dan iklim kerja sama dan kehangatan psikologis- dan sumber daya personal sehari-hari.

Peneliti memahami bahwa penelitian ini masih memiliki beberapa keterbatasan. Keterbatasan utama dalam penelitian ini adalah pada subjek penelitiannya yang meskipun berasal dari berbagai sekolah inklusi dan tingkatan pendidikan sekolah, namun berada dalam satu naungan yayasan sekolah yang sama. Hal ini membuat ada kemungkinan variasi data menjadi lebih terbatas. Selain itu, 
peneliti juga masih berfokus pada variabel kebahagiaan autentik -yang berasal dari sumber daya personal- guna mengungkap keterkaitannya terhadap keterikatan kerja. Faktor-faktor lain yang berkaitan dengan sumber daya kerja seperti penghargaan, dukungan organisasi dan atasan, otonomi, kesempatan untuk belajar, dan umpan balik kinerja (Schaufeli et al, 2009; Sohrabizadeh \& Sayfouri, 2014) yang diyakini turut memengaruhi keterikatan kerja, menjadi variabel yang tidak dipertimbangkan oleh peneliti.

\section{Simpulan}

Berdasarkan hasil penelitian dapat disimpulkan bahwa semakin tinggi kebahagiaan autentik yang dimiliki oleh guru di sekolah inklusi, maka semakin tinggi pula keterikatan kerja yang dialami oleh guru tersebut. Sebaliknya, semakin rendah kebahagiaan autentik yang dimiliki oleh guru di sekolah inklusi, maka semakin rendah pula keterikatan kerja yang dimilikinya.

\section{Saran}

Peneliti selanjutnya dapat mengambil data dari beragam sekolah inklusi agar data dapat mewakili populasi. Selain itu, pihak manajemen sekolah diharapkan dapat membekali guru di sekolah inklusi dengan keterampilan untuk membangun dan mengembangkan kebahagiaan autentik serta menciptakan sekolah sebagai lingkungan tempat kerja yang menyenangkan dan suportif guna menumbuhkan rasa bahagia, semangat, dan antusiasme guru terhadap pekerjaannya. Sementara itu, bagi para peneliti yang tertarik dengan tema serupa diharapkan mampu menggali berbagai variabel psikologis lainnya yang dapat mengukuhkan keterikatan kerja.

\section{Referensi}

Adekola, B. (2011). Antecedents and consequences of work engagement among managers and professionals in Nigeria. Journal of Economics, Management and Trade, 1(2), 83-99. h t tp: / / www.journaljemt.com / index.php/JEMT/article/view/30058

Arcidiacono, C., \& Martino, S. D. (2016). A critical analysis of happiness and wellbeing. Where we stand now, where we need to go. Community Psychology in Global Perspective, 2(1), 6-35. https:// doi.org/10.1285/i24212113v2i1p6

Ariani, D. . (2013). The relationship between employee engagement, organizational citizenship behavior, and counterproductive work behavior. International Journal of Business Administration, 4(2), 46-56. https:// doi.org/10.5430/ijba.v4n2p46

Asfiyah, E. Y., \& Kurniawati, E. (2014). Hubungan antara resiliensi dengan work engagement pada guru SLB. Psikoislamika: Jurnal Psikologi Dan Psikologi Islam, 11(2). https://doi.org/ 10.18860/psi.v11i2.6385

Bailey, C., Madden, A., Alfes, K., \& Fletcher, L. (2015). The meaning, antecedents and outcomes of employee engagement: a narrative synthesis. International Journal of Management Reviews, 19(1), 31-53. https://doi.org/10.1111/ijmr.12077

Bakker, A. B., \& Bal, P. M. (2010). Weekly work engagement and performance: A study among starting teachers. Journal of occupational and Organizational 
Psychology, 83(1), 189-206. https:// doi.org/10.1348/096317909X402596

Bakker, A. B. (2011). An evidence-based model of work engagement. Current Directions in Psychological Science, 20(4), 265-269. h t tp s : / / doi .org / 10.1177 / 0963721411414534

Bakker, A. B, \& Leiter, M. P. (2010). A work engagement: $A$ handbook of essential theory and research. Psychology Press. h t tps: / / doi.org / 10.4324 / 9780203853047

Bakker, Arnold B, \& Demerouti, E. (2008). Towards a model of work engagement. Career Development International, 13(3), 209-223. https://doi.org/10.1108/ 13620430810870476

Batainerh, K. A. (2019). Impact of work-life balance, happiness at work, on employee performance. International Business Research, 12(2), 99-112. https:// doi.org/10.5539/ibr.v12n2p99

Batista-Taran, L. C., Shuck, M. B., Gutierrez, C. C., \& Baralt, S. (2009). The role of leadership style in employee engagement. In Plakhotnik M. S., S. M. Nielsen, \& D. M. Pane (Eds.), Proceedings of the eighth annual College of Education \& GSN research conference (pp. 15-20). Florida International University.

Bhatnagar, J. (2007). Talent management strategy of employee engagement in Indian ITES employees: key to retention. Employee Relations, 29(6), 640-663. h t tp s: / / doi.org / 10.1108 / 01425450710826122

Botha, C., \& Mostert, K. (2014). A structural model of job resources, organizational and individual strengths use and work engagement. SA Journal of Industrial Psychology, 40(1), 1-11. https://doi.org/ 10.4102/sajip.v40i1.1135

Burke, R. J., Koyuncu, M., Fiksenbaum, L., \& Tekin, Y. (2013). Antecedents and consequences of work engagement among frontline employees in Turkish hotels. Journal of Transnational Management, 18(3), 191-203. https:// d o i . o r g / 10 . 1080 / 15475778.2013.817243

Chon, M. A., \& Fredrickson, B. L. (2006). Beyond the moment, beyond the self: Shared ground between selective investment theory and the broaden-and-build theory of positive emotion. Psychology Inquiry, 17(1), 39-44. https://www.jstor.org/ stable/20447297

Christian, M. ., Garza, A. ., \& Slaughter, J.. (2011). Work engagement: a quantitative review a test of its relations with task and contextual performance. Personnel Psychology, 64(1), 89-136. https:// do i .org / $10.1111 / \mathrm{j} .1744$ 6570.2010.01203.x

De Stasio, S., Fiorilli, C., Benevene, P., Boldrini, F., Ragni, B., Pepe, A., \& Briegas, J. (2019). Subjective happiness and compassion are enough to increase teachers' work engagement? Frontiers in Psychology, 10, 2268. https:// doi.org/10.3389/fpsyg.2019.02268

Elisa, S., \& Wrastari, A. T. (2013). Sikap guru terhadap pendidikan inklusi ditinjau dari faktor pembentuk sikap. Jurnal Psikologi Perkembangan Dan Pendidikan, 2(1), 110. http://journalunair.ac.id/filerPDF/ 110810216_Ringkasan.pdf

Els, C., Viljoen, J., de Beer, L., \& BrandLabuschagne, L. (2016). The mediating e ect of leader-mem- ber exchange between strengths use and work engagement. Journal of Psychology in Africa, 26(1), 22-28. https://doi.org/ 10.1080/14330237.2016.1149278

Endres, G. M., \& Smoak, L. M. (2008). The human resource craze: human performance improvement and employee engagement. Organization Development Journal, 26(1), 69-78. https://psycnetapa.org/record/201008674-008

Field, L. K., \& Buitendach, J. H. (2011). Happiness, work engagement and organisational commitment of support 
staff at a tertiary education institution in South Africa. SA Journal of Industrial Psychology, 37(1), 1-10. https://doi.org/ 10.4102/sajip.v37i1.946

Fredrickson, B. L., \& Joiner, T. (2002). Positive emotions trigger upward spirals toward emotional well-being. Psychological Science, 13, 172-175. https://doi.org/ 10.1111/1467-9280.00431

Galaterou, J., \& Antoniou, A.-S. (2017). Teacher's attitude towards inclusive education: the role of job stressors and demographic parameters. International Journal of Special Education, 32(4), 643-656. https://eric.ed.gov/?id=EJ1184123

Gallup Consulting. (2008). Employee engagement: What's your engagement ratio? https://hr-portal.ru/files/ Employee_Engagement_Overview_Brochure.pdf

Gorgievski, M., \& Schaufeli, W. (2010). Work engagement and workaholism: comparing the self-employed and salaried employees. Journal of Positive Psychology, 5(10), 83-96. https:// doi.org/10.1080/17439760903509606

Gupta, V. (2012). Importantce of being happy at work. International Journal of Research and Development: A Management Review, 1(1), 9-14. http://irdindia.in/ journal_ijrdmr/pdf/vol1_iss1/2.pdf

Hermanto, S. P. (2010). Penyelenggaraan pendidikan inklusif membutuhkan keseriusan manajemen sekolah. Jurnal Pendidikan Khusus, 6(1), 65-82. https:/ /doi.org/10.21831/jpk.v6i2.6737

Høigaard, R., Giske, R., \& Sundsli, K. (2011). Newly qualified teachers' work engagement and teacher efficacy influences on job satisfaction, burnout, and the intention to quit. European Journal of Teacher Education, 35(3), 347357. https://doi.org/10.1080/ 02619768.2011 .633993

Lyubomirsky, S., \& King, L. (2013). How do simple positive activities increase wellbeing? Current directions in psychological science. Psychological
Science, 22(1), 57-62. https://doi.org/ $10.1177 / 0963721412469809$

Mäkinen, M. (2013). Becoming engaged in inclusive practices: narrative reflections on teaching as descriptors of teachers' work engagement. Teaching and Teacher Education, 35, 51-61. https://doi.org/ 10.1016/j.tate.2013.05.005

Minghui, L., Lei, H., Xiaomeng, C., \& Potmìšilc, M. (2018). Teacher efficacy, work engagement, and social support among Chinese special education school teachers. Frontiers in Psychology, 9. h t tps: //doi.org/10.3389/ fpsyg.2018.00648

Money, K., Hillenbrand, C., \& Da Camara, N. (2008). Putting positive psychology to work in organisations. Journal of General Management, 34, 21-36. https://doi.org/ 10.1177/030630700903400302

Mphahlele, P., Els, C., De Beer, L. T., \& Mostert, K. (2018). Investigating strengths and de cits to increase work engagement: A longitudinal study in the mining industry. SA Journal of Human Resource Management, 16, 1-16. https://doi.org/ 10.4102/sajhrm.v16i0.900

Newman, D. A., Joseph, D. L., \& Hulin, C. L. (2010). Job attitudes and employee engagement: Considering the attitude " $A$ factor."

Peterson, C. (2005). Authentic happiness inventory. Positive Psychology Center of University of Pennsylvania. https:// www.authentichappiness.sas.upenn.edu/ questionnaires/authentic-happinessinventory

Rooy, D. L. V, Whitman, D. S., Hart, D., \& Caleo, S. (2011). Measuring employee engagement during a financial downturn: business imperative or nuisance? Journal of Business and Psychology, 26(2), 147-152. https://doi.org/10.1007/ s10869-011-9225-6

Runhaar, P., Sanders, K., \& Konermann, J. (2013). Teacher's work engagement: 
considering interaction with pupils and human resources practices as job resources. Journal of Applied Social Psychology, 43, 2017-2030. https:// doi.org/10.1111/jasp.12155

Schaufeli, W. B. (2013). What is engagement? In C. Truss, K. Alfes, R. Delbridge, A. Schantz, \& E. Soan (Eds.), Employment engagement in theory and practice. Routledge.

Schaufeli, W. B., \& Bakker, A. B. (2003). UWES, Utrecht Work Engagement Scale. Occupational Health Psychology Unit Utrecht University. https://doi.org/ 10.1037/t07164-000

Schaufeli, W. B., Bakker, A. B., \& Rhenens, W. V. (2009). How changes in job demands and resources predict burnout, work engagement, and sickness absenteeism. Journal of Organizational Behaviour, 30, 893-917. https://doi.org/10.1002/ job.595

Schaufeli, W., Salanova, M., González-romá, V., \& Bakker, A. B. (2002). The measurement of engagement and burnout: A two sample confirmatory factor analytic approach. Journal of Happiness Studies, 3(1), 71-92. https://doi.org/10.1023/ A:1015630930326

Schueller, S. M., \& Seligman, M. E. P. (2010). Pursuit of pleasure, engagement, and meaning: Relationships to subjective and objective measures of well-being. The Journal of Positive Psychology, 5(4), 253263. https://doi.org/10.1080/ 17439761003794130

Seligman, M. E. (2012). Flourish: A visionary new understanding of happiness and wellbeing. Simon and Schuster.

Seligman, M. E. P. (2005). Menciptakan Kebahagiaan dengan Psikologi Positif (Authentic Happiness). PT. Mizan Pustaka.

Sohrabizadeh, S., \& Sayfouri, N. (2014). Antecedents and consequences of work engagement among nurses. Iranian Red Crescent Medical Journal, 16(11), 1-8. https://doi.org/10.5812/ircmj.16351
Sunanto, J. (2007). Manajemen pendidikan inklusif. Pelatihan Kompetensi Tenaga Kependidikan bagi Kepala/Guru SDLB, SLB, dan Sekolah Terpadu se-Nusa Tenggara Timur.

Sungkit, F. N., \& Meiyanto, S. (2015). Pengaruh job enrichment terhadap employee engagement melalui psychological meaningfulness sebagai mediator. Gadjah Mada Journal of Psychology (GamaJoP), 1(1), 61-73. h t tp s://doi.org/10.22146/ gamajop.7354

Swart, J., \& Rothmann, S. (2012). Authentic happiness of managers, and individual and organisational outcomes. South African Journal of Psychology, 42(4), 492508. https://doi.org/10.1177/ 008124631204200404

Veenhoven, R. (2001). Quality of life and happiness: Not quite the same.

Wartomo. (2016). Pelaksanaan model pendidikan inklusif di sekolah wilayah D.I.Yogyakarta. Mukaddimah Jurnal Psikologi Islam, 1(1), 197-220. https:// doi.org/10.14421/mjsi.11.1340

Xanthopoulou, D., Bakker, A. B., Demerouti, E., \& Schaufeli, W. B. (2012). A diary study on the happy worker: how job resources relate to positive emotions and personal resources. European Journal of Work and Organizational Psychology, 21(4), 489517. https://doi.org/10.1080/ 1359432X.2011.584386

Yang, N., Chen, C. C., Choi, J., \& Zou, Y. (2000). Sources of work family conflict: A Sino U.S. comparison of the effects of work and family demands. Academy of Management Journal, 43(1), 113-123. https://doi.org/10.5465/1556390

Zeng, G., Chen, X., Cheung, H. Y., \& Peng, K. (2019). Teachers' growth mindset and work engagement in the Chinese educational context: well-being and perseverance of effort as mediators. Frontiers in Psychology, 10. https:// doi.org/10.3389/fpsyg.2019.00839 
Received 4 January 2020

Revised 28 April 2020

Accepted 8 May 2020 